\title{
Antibiotic sensitivities of gonococci isolated in Rotterdam and results of treatment with cefuroxime
}

\author{
K C NAYYAR,* M F MICHEL, † AND E STOLZ* \\ From the Departments of ${ }^{*}$ Dermatology and + Microbiology, University Hospital Rotterdam-Dijkzigt, \\ Rotterdam, the Netherlands
}

SUMMARY In a study of the efficacy of cefuroxime in the treatment of 278 cases of acute gonorrhoea (including rectal and pharyngeal infections and infections due to penicillinase-producing Neisseria gonorrhoeae), high cure rates were found for both male $(98 \cdot 8 \%)$ and female patients $(98 \cdot 6 \%)$. Disadvantages of this treatment are its high cost and the relatively high proportion of patients who develop postgonococcal urethritis.

\section{Introduction}

Penicillin has been the drug of choice in the treatment of gonorrhoea ever since its discovery. However, in view of the emergence of penicillinaseproducing strains of Neisseria gonorrhoeae (PPNG), it has become necessary to reassess the role of penicillins and ampicillins in the treatment of gonorrhoea. In the Netherlands infections caused by PPNG strains are becoming a serious problem. In the second quarter of 1979 about 2500 cases of gonorrhoea, and about $60(2 \cdot 5 \%)$ cases caused by PPNG strains, were reported to the Inspector of Health. ${ }^{1}$

The continued use of penicillins and ampicillins as drugs of first choice will probably cause several PPNG strains to become resistant to the drugs and also an unnecessary delay in the effective treatment of patients with infections due to PPNG strains. From an epidemiological point of view this is highly undesirable and theoretically a further increase in the proportion of infections due to PPNG strains can be expected. At a time when amoxycillin $\mathbf{3} \mathrm{g}$ and probenecid $1 \mathrm{~g}$ orally was standard treatment in our clinic five $(25 \%)$ out of 20 patients harbouring PPNG strains could not be followed up. Of the remaining 15 patients, gonococci could not be isolated in two one week after treatment. The other 13 patients still harboured PPNG strains 4-7 days after treatment. ${ }^{1}$

For this reason it became necessary for us to look for alternative treatments. $\beta$-lactamase-resistant cephalosporins are drugs which can be used in infections due to PPNG strains. ${ }^{2}$

Address for reprints: Dr K C Nayyar, Department of Dermatology, University Hospital Rotterdam-Dijkzigt, Rotterdam, the Netherlands

Received for publication 5 November 1979
Recently, Berg et $a l^{3}$ investigated the efficacy of cefoxitin in cases of gonorrhoea due to PPNG as well as to non-PPNG strains. In both types of infection treatment with cefoxitin was completely successful. One of the other promising $\beta$-lactamase-resistant cephalosporins is cefuroxime, a semisynthetic analogue of cephalosporin $\mathrm{C}$; it has a broadspectrum activity, is not absorbed orally, and has to be administered parenterally.

In this study, the efficacy of cefuroxime $(1 \cdot 5 \mathrm{~g}$ administered in a single intramuscular injection) in the routine treatment of uncomplicated urogenital, rectal, and pharyngeal gonorrhoea due to nonPPNG and PPNG strains is evaluated.

\section{Patients and methods}

Patients diagnosed as having gonorrhoea in the venereal disease clinic of the dermatovenereology department of the University Hospital RotterdamDijkzigt between June 1979 and August 1979 were included in this study. Sailors, prostitutes, pregnant women, and patients with a history of penicillin allergy were not included. A total of 278 patients (197 men and 81 women) with urogenital, rectal, or pharyngeal gonorrhoea were treated.

\section{DIAGNOSIS}

The diagnosis of gonorrhoea in these patients was based on a positive result to culture for $N$ gonorrhoeae. The diagnostic procedure in these patients was performed as described previously. ${ }^{4}$

All strains were screened for penicillinase production by the phenol red method. ${ }^{5}$

\section{DRUG SENSITIVITIES}

Of the first 157 strains isolated (116 strains from male and 41 strains from female patients) sensitivities to 
amoxycillin, penicillin, tetracycline, and cefuroxime were determined by the agar dilution method as previously described. ${ }^{6}$ The amoxycillin, penicillin, tetracycline, and cefuroxime concentrations were varied in doubling dilutions over the following ranges: $0 \cdot 0025-2 \cdot 56 \mu \mathrm{g} / \mathrm{ml}$ (amoxycillin and penicillin); $0.01-2.56 \mu \mathrm{g} / \mathrm{ml}$ (tetracycline); and $0.0025-0.64 \mu \mathrm{g} / \mathrm{ml}$ (cefuroxime). Sensitivities were expressed as minimum inhibitory concentrations (MICs) in $\mu \mathrm{g} / \mathrm{ml}$. Relative resistance was arbitrarily defined as follows: amoxycillin, MIC $>0 \cdot 16 \mu \mathrm{g} / \mathrm{ml}$; penicillin, MIC $>0.08 \mu \mathrm{g} / \mathrm{ml}$; tetracycline, MIC $\geqslant 1.28 \mu \mathrm{g} / \mathrm{ml}$; and cefuroxime, MIC $\geqslant 0.04 \mu \mathrm{g} / \mathrm{ml}$. Strains having an MIC $\geqslant 2.56 \mu \mathrm{g} / \mathrm{ml}$ for amoxycillin and penicillin were considered to be resistant.

\section{FOLLOW UP}

The patients were asked to return for review 7-11 days after treatment. At review, examination was the same as that performed before treatment. Any patient found to have gonorrhoea during the 11 days after treatment, and who admitted to new sexual contact within this period, was regarded as a case of reinfection. If the patient denied having had any sexual contact in this period and still had gonorrhoea, this was regarded as a treatment failure.

The male patients were investigated for postgonococcal urethritis (PGU) on the basis of the sedimentation results in the two-glass urine test $(>10$ pus cells/high power field $(\times 25)$.

\section{Results}

\section{DIAGNOSIS}

In the male patients, the diagnosis of gonorrhoea was based on positive culture results from the urethra in 190 , from the urethra and throat in two, and from the rectum in five. In the female patients, the diagnosis was based on positive culture results from the urethra in one, from the cervix in six, from the rectum in one, from the cervix and urethra in 50 , from the cervix and rectum in four, from the cervix, urethra, and rectum in 16, from the cervix, urethra, and throat in two, and from the cervix, urethra, rectum, and throat in one. Eleven $(4 \%)$ patients (seven $(3.6 \%)$ male and four (4.9\%) female) harboured PPNG strains. Of the 11 PPNG strains, 10 (six from male and four from female patients) were included in the 157 strains tested for sensitivity to the four antibiotics mentioned earlier.

\section{DRUG SENSITIVITIES}

The distribution of the sensitivities and the percentage of (relative) resistance to amoxycillin, penicillin, tetracycline, and cefuroxime are given in table I. All the 10 PPNG strains had an MIC $>2.56 \mu \mathrm{g} / \mathrm{ml}$ for amoxycillin and penicillin. Nine of these 10 strains were tested for sensitivity to cefuroxime and tetracycline. All had an MIC of $0.16 \mu \mathrm{g} / \mathrm{ml}$ for cefuroxime. The MIC of tetracycline was $2.56 \mu \mathrm{g} / \mathrm{ml}$ for one strain and $0.64 \mu \mathrm{g} / \mathrm{ml}$ for eight strains.

TABLE Sensitivities of 157 gonococcal strains to amoxycillin, penicillin, tetracycline, and cefuroxime and percentage with relative resistance to the four drugs

\begin{tabular}{|c|c|c|c|c|c|c|c|c|c|c|c|c|c|c|}
\hline \multirow[b]{2}{*}{ Drug } & \multicolumn{12}{|c|}{ \% of gonococcal strains with MICs $(\mu \mathrm{g} / \mathrm{ml})$ as follows: } & \multirow[b]{2}{*}{$\begin{array}{l}\text { Total } \\
\text { No }\end{array}$} & \multirow[b]{2}{*}{$\begin{array}{l}\% \text { with relative } \\
\text { resistancet }\end{array}$} \\
\hline & 0.0025 & 0.005 & $0 \cdot 01$ & $0 \cdot 02$ & $0 \cdot 04$ & 0.08 & $0 \cdot 16$ & $0 \cdot 32$ & 0.64 & $1 \cdot 28$ & $2 \cdot 56$ & $>2 \cdot 56^{*}$ & & \\
\hline $\begin{array}{l}\underset{M \neq}{\text { Amoxycillin }} \\
\mathrm{F} \neq \\
M+F\end{array}$ & & & $\begin{array}{l}4 \\
0 \\
3\end{array}$ & $\begin{array}{r}13 \\
7 \\
11\end{array}$ & $\begin{array}{l}19 \\
32 \\
22\end{array}$ & $\begin{array}{r}8 \\
12 \\
9\end{array}$ & $\begin{array}{l}29 \\
27 \\
29\end{array}$ & $\begin{array}{l}17 \\
10 \\
15\end{array}$ & $\begin{array}{l}4 \\
0 \\
3\end{array}$ & $\begin{array}{l}0 \\
2 \\
1\end{array}$ & & $\begin{array}{r}5 \\
10 \\
6\end{array}$ & $\begin{array}{r}116 \\
41 \\
157\end{array}$ & $\begin{array}{l}56 \\
49 \\
54\end{array}$ \\
\hline $\begin{array}{l}\text { Penicillin } \\
\underset{\mathbf{M}}{\mathbf{F}} \\
\mathbf{M}+\mathbf{F}\end{array}$ & $\begin{array}{l}1 \\
0 \\
1\end{array}$ & $\begin{array}{l}9 \\
0 \\
6\end{array}$ & $\begin{array}{l}18 \\
22 \\
19\end{array}$ & $\begin{array}{r}9 \\
22 \\
13\end{array}$ & $\begin{array}{r}9 \\
10 \\
10\end{array}$ & $\begin{array}{l}25 \\
22 \\
24\end{array}$ & $\begin{array}{r}11 \\
5 \\
10\end{array}$ & $\begin{array}{l}6 \\
2 \\
5\end{array}$ & $\begin{array}{l}6 \\
5 \\
6\end{array}$ & $\begin{array}{l}0 \\
0 \\
0\end{array}$ & $\begin{array}{l}2 \\
1\end{array}$ & $\begin{array}{r}5 \\
10 \\
6\end{array}$ & $\begin{array}{r}116 \\
4 \\
157\end{array}$ & $\begin{array}{l}53 \\
46 \\
52\end{array}$ \\
\hline $\begin{array}{l}\text { Tetracycline } \\
\quad \mathbf{M} \\
\mathbf{F} \\
\mathbf{M}+\mathbf{F}\end{array}$ & & & & $\begin{array}{l}1 \\
0 \\
1\end{array}$ & $\begin{array}{l}0 \\
0 \\
0\end{array}$ & $\begin{array}{l}0 \\
2 \\
1\end{array}$ & $\begin{array}{r}10 \\
5 \\
8\end{array}$ & $\begin{array}{l}47 \\
54 \\
49\end{array}$ & $\begin{array}{l}10 \\
10 \\
10\end{array}$ & $\begin{array}{l}23 \\
17 \\
21\end{array}$ & $\begin{array}{l}10 \\
12 \\
11\end{array}$ & & $\begin{array}{r}115 \\
41 \\
156\end{array}$ & $\begin{array}{l}33 \\
29 \\
32\end{array}$ \\
\hline $\begin{array}{l}\text { Cefuroxime } \\
\underset{M}{\mathbf{F}} \\
\mathbf{M}+\mathbf{F}\end{array}$ & & $\begin{array}{l}8 \\
0 \\
6\end{array}$ & $\begin{array}{l}20 \\
24 \\
21\end{array}$ & $\begin{array}{l}28 \\
34 \\
29\end{array}$ & $\begin{array}{l}16 \\
15 \\
15\end{array}$ & $\begin{array}{r}11 \\
5 \\
10\end{array}$ & $\begin{array}{l}15 \\
22 \\
17\end{array}$ & $\begin{array}{l}3 \\
0 \\
2\end{array}$ & & & & & $\begin{array}{c}115 \S \\
41 \\
156\end{array}$ & $\begin{array}{l}44 \\
41 \\
44\end{array}$ \\
\hline
\end{tabular}


FOLLOW UP

Of the 267 patients infected with non-PPNG strains (190 male and 77 female), $20(7 \cdot 5 \%)$ patients (15 male, $7.9 \%$ and five female, $6 \cdot 5 \%$ ) did not return for follow up. Of the remaining 175 male patients, $173(98 \cdot 8 \%)$ were cured. One $(0 \cdot 6 \%)$ patient admitted reinfection; another $(0 \cdot 6 \%)$ was not cured at the first review one week after treatment. The MIC of cefuroxime for the isolated strains was not determined. Forty-seven $(26 \cdot 9 \%)$ patients developed postgonococcal urethritis. Of the 72 female patients who did return, $71(98 \cdot 6 \%)$ were cured. One $(1 \cdot 4 \%)$ patient was still infected one week after treatment; she admitted re-exposure to infection.

Of all the 11 patients infected with PPNG strains (seven male and four female) one male patient was not available for follow up; the remaining 10 patients were all cured, as were all patients with rectal or pharyngeal gonorrhoea.

No serious side effects were observed. Two patients developed an erythematous maculopapular rash. Twenty-one patients did complain of transient pain at the injection site.

\section{Discussion}

The prevalence of PPNG strains in our study population (4\%) corresponds with that in the Netherlands during the second quarter of $1979(2 \cdot 5 \%)$.

The proportion of relatively resistant strains to amoxycillin, penicillin, tetracycline, and cefuroxime was higher in this study than in those performed in 1976 and between 1971 and 1972 of gonococci isolated from male and female civilian patients attending our Rotterdam outpatient department. ${ }^{67}$ Even when the PPNG strains are excluded, the proportion of relatively resistant strains to amoxycillin, penicillin, tetracycline, and cefuroxime are still higher in this study than in the earlier studies (table II).

The relative resistance to amoxycillin and tetracycline has markedly increased. Amoxycillin is used as the treatment of choice in our clinic and

TABLE II Percentage of relatively resistant strains to amoxycillin, penicillin, tetracycline, and cefuroxime for gonococcal strains isolated in 1971/2, 1976, and 1979

\begin{tabular}{lllll}
\hline & \multicolumn{2}{l}{$\%$ of strains relatively resistant } \\
\cline { 2 - 5 } & \multicolumn{2}{l}{ Non-PPNG } & Non-PPNG+PPNG \\
\cline { 2 - 5 } & $1971 / 2$ & 1976 & 1979 & $\begin{array}{l}1979 \\
(n=146) \\
(n=430)\end{array}$ \\
\cline { 2 - 5 } Drug & $(n=147)$ & $(n=157)$ \\
\hline Amoxycillin & 38 & 31 & 51 & 54 \\
Penicillin & 37 & 40 & 48 & 52 \\
Tetracycline & 15 & 8 & 29 & 32 \\
Cefuroxime & & 35 & 40 & 44 \\
\hline
\end{tabular}

elsewhere in the Netherlands, and tetracycline is sometimes used for patients with gonorrhoea. Our findings need to be corroborated by larger scale studies testing sensitivities to a broader range of antibiotics in our clinic as well as in other European centres.

Only one of the PPNG strains tested was relatively resistant to tetracycline. The MICs for cefuroxime were also not very high $(0 \cdot 16 \mu \mathrm{g} / \mathrm{ml})$.

Despite a small increase in the incidence of relative resistance to cefuroxime in only one male patient, treatment failure with cefuroxime was noted. According to Fowler and Rahim, ${ }^{8}$ the proportion of patients developing postgonococcal urethritis after treatment with cefuroxime is similar to that after treatment with penicillin or ampicillin. This is confirmed by our data.

The results of this study show that cefuroxime $1.5 \mathrm{~g}$ in a single intramuscular dose is safe and highly effective in the treatment of gonorrhoea whether or not the patient is harbouring a PPNG strain. One drawback of treatment with cefuroxime, as well as with ampicillin and penicillin, is the high incidence of postgonococcal urethritis in male patients. Another disadvantage is the high cost of treatment with cefuroxime in the Netherlands; treatment with cefuroxime costs $75 \%$ more than with amoxycillin and probenecid. Thus, the advantages and the disadvantages of treatment with cefuroxime have to be considered before cefuroxime is used as a drug of first choice in the treatment of gonorrhoea. This decision will depend on the increased prevalence of PPNG strains, on the availability of other first-line drugs for treating uncomplicated gonorrhoea, on the possibility that gonococci will rapidly develop resistance to cefuroxime in vitro and in vivo, and on the costs involved in a change of drug regimen.

\section{References}

1. Nayyar KC, Noble RC, Michel MF, Stolz E. Gonorrhoea in Rotterdam caused by penicillinase-producing gonococci. $\mathrm{Br} J$ Vener Dis 1980;56:244-8.

2. O'Callaghan CH, Sykes RB, Griffiths A, Thornton JE. Cefuroxime a new cephalosporin antibiotic activity in vitro. Antimicrob Agent Chemother 1976;9:511-9.

3. Berg SW, Kilpatrick ME, Harrison WO, McCutchan JA. Cefoxitin treatment of penicillinase-producing Neisseria gonorrhoeae. N Engl J Med 1979;301:509-11.

4. Stolz E. Diagnostic aspects of gonorrhoea. Thesis. Rotterdam, 1974.

5. Phillips $\mathrm{CW}$, Aller $\mathrm{RC}$, Cohen $\mathrm{CN}$. Penicillinase-producing Neisseria gonorrhoeae. Lancet 1976; ii:960.

6. Stolz E, Zwart HGF, Michel MF. Sensitivity to ampicillin, penicillin and tetracycline of gonococci in Rotterdam. $\mathrm{Br} J$ Vener Dis 1974; 50:202-7.

7. Stolz E, Michel MF, Schuller JL, de Koning GAJ. Sensitivity to gonococcus strains isolated in Rotterdam to epicillin, ampicillin, penicillin and tetracycline. Dermatologica 1978; 157: 158-63.

8. Fowler W, Rahim G. Cefuroxime and postgonococcal urethritis. Roy Soc Med 1977; 70 suppl 90:131-3. 